\title{
Diversity in the Neural Circuitry of Cold Sensing Revealed by Genetic Axonal Labeling of Transient Receptor Potential Melastatin 8 Neurons
}

\author{
Yoshio Takashima, ${ }^{1}$ Richard L. Daniels, ${ }^{1}$ Wendy Knowlton, ${ }^{1}$ James Teng, ${ }^{3}$ Emily R. Liman, ${ }^{1,2}$ and David D. McKemy ${ }^{1,2,3}$ \\ ${ }^{1}$ Neuroscience Graduate Program, ${ }^{2}$ Neurobiology Section, Department of Biological Sciences, and ${ }^{3}$ School of Dentistry, University of Southern California, \\ Los Angeles, California 90089
}

\begin{abstract}
Sensory nerves detect an extensive array of somatosensory stimuli, including environmental temperatures. Despite activating only a small cohort of sensory neurons, cold temperatures generate a variety of distinct sensations that range from pleasantly cool to painfully aching, prickling, and burning. Psychophysical and functional data show that cold responses are mediated by both C-and $\mathrm{A} \delta$-fibers with separate peripheral receptive zones, each of which likely provides one or more of these distinct cold sensations. With this diversity in the neural basis for cold, it is remarkable that the majority of cold responses in vivo are dependent on the cold and menthol receptor transient receptor potential melastatin 8 (TRPM8). TRPM8-null mice are deficient in temperature discrimination, detection of noxious cold temperatures, injury-evoked hypersensitivity to cold, and nocifensive responses to cooling compounds. To determine how TRPM8 plays such a critical yet diverse role in cold signaling, we generated mice expressing a genetically encoded axonal tracer in TRPM8 neurons. Based on tracer expression, we show that TRPM8 neurons bear the neurochemical hallmarks of both C-and A $\delta$-fibers, and presumptive nociceptors and non-nociceptors. More strikingly, TRPM8 axons diffusely innervate the skin and oral cavity, terminating in peripheral zones that contain nerve endings mediating distinct perceptions of innocuous cool, noxious cold, and first- and second-cold pain. These results further demonstrate that the peripheral neural circuitry of cold sensing is cellularly and anatomically complex, yet suggests that cold fibers, caused by the diverse neuronal context of TRPM8 expression, use a single molecular sensor to convey a wide range of cold sensations.
\end{abstract}

Key words: TRPM8; cold temperatures; menthol; neural circuit; sensory neuron; transgenic

\section{Introduction}

Primary afferent neurons are the initial site in the detection of environmental stimuli, recognizing and transmitting discrete sensory cues from the periphery to the spinal cord (Julius and Basbaum, 2001). A fundamental question is how the diverse array of sensory cues, carried on ascending afferent nerve fibers, are encoded and integrated as they travel centrally (Craig, 2003). In addressing this question, the ability to identify neural circuits responsible for transducing specific modes of environmental stimuli is essential and requires modality-specific markers of primary afferents, which have been lacking until recently. Indeed, the cloning of molecules that detect specific stimuli (i.e., hot vs cold temperatures) has been a key advance in understanding the mechanisms of somatosensation. Chief among these are several

Received Aug. 16, 2007; revised Nov. 9, 2007; accepted Nov. 12, 2007.

This work was supported by National Institutes of Health Grants DC0454 (E.R.L.) and NS051532 and NS054069 (D.D.M.). We thank L. Ma, M. Arbeitman, D. Arnold, S. Butler, and J. Chan for critical reading of this manuscript and helpful criticisms and discussions, N. Heintz for the pLD53.SCA-E-B shuttle vector, Y. Chai and T. Yamaza for help with tooth immunochemistry, N. Segil for help with BAC DNA preparation, M. Tominaga for providing TRPM8 antiserum, and B. $\mathrm{Ng}$ and $\mathrm{Q}$. Wu for help with immunochemistry and microscopy.

Correspondence should be addressed to Dr. David D. McKemy, 3641 Watt Way, HNB 228, University of Southern California, Los Angeles, CA 90089. E-mail: mckemy@usc.edu.

D01:10.1523/JNEUROSCI.4578-07.2007

Copyright $\odot 2007$ Society for Neuroscience 0270-6474/07/2714147-11\$15.00/0 excitatory ion channels of the transient receptor potential (TRP) family that are directly gated by temperature change (Jordt et al., 2003). These molecular thermoreceptors demarcate neural circuits involved in communicating temperature, much in the way that odorant receptors have added to our understanding of the neural mechanisms of olfaction (Reed, 2004).

Of temperature-sensitive TRP channels, only one has been shown unequivocally to be involved in cold sensation, the cold and menthol receptor transient receptor potential melastatin 8 (TRPM8) (Daniels and McKemy, 2007). In vitro, TRPM8 currents are evoked as temperatures drop below $\sim 26^{\circ} \mathrm{C}$, and over a range of both innocuous cool and noxious cold temperatures (McKemy et al., 2002; Peier et al., 2002). Mice lacking TRPM8 are deficient in detecting innocuous cool temperatures and exhibit a partially defective phenotype in responding to noxious cold (Bautista et al., 2007; Colburn et al., 2007; Dhaka et al., 2007). Moreover, activation of TRPM8 is required for the analgesia provided by cooling and cooling compounds (Proudfoot et al., 2006; Dhaka et al., 2007) and, paradoxically, is essential in injuryevoked hypersensitivity to cold (Colburn et al., 2007; Dhaka et al., 2007). Thus, TRPM8 plays a principal role in the perception of cold temperatures and raises the question: how can a single receptor be involved in multiple, and in some cases antagonistic (pain vs analgesia), aspects of sensory signaling? 
To begin to address this question we have generated transgenic mice expressing a genetically encoded axonal tracer that fluorescently labels TRPM8 neurons and axons in vivo, and have examined their neurochemical phenotype and central and peripheral projections. Consistent with the broad range of functional roles of the channel, TRPM8 neurons express markers of nociceptors as well as non-nociceptors, and have axonal properties indicative of both $\mathrm{A} \delta$ - and C-fibers. Moreover, in the tooth, TRPM8 axons terminate in at least two distinct receptive fields in which cold fibers are known to mediate temporally and perceptually distinct pain sensations (Jyvasjarvi and Kniffki, 1987). Last, the peripheral projections of these fibers asymmetrically innervate cutaneous regions known to have noxious cold fibers, as well as different domains containing innocuous cool fibers. Thus, our findings reveal that the neural circuitry of cold sensing is rich in complexity and provides a cellular and anatomical rationale for the multifaceted role of TRPM8 in cold thermosensation.

\section{Materials and Methods}

Molecular biology. The Trpm8 bacterial artificial chromosome (BAC) clone was modified by homologous recombination as described by Gong et al. (2002), targeting an enhanced green fluorescent protein (GFP) transgene to the second exon at nucleotide position 1927 in the Trpms gene (numbering based on the Ensembl Genome Browser; gene ID, ENSMUSG00000036251), which deletes 317 bp of the remainder of the exon and adjacent intron. DNA fragments (405 and $460 \mathrm{bp}$ ) flanking this site were PCR-amplified with PfuUltra HF polymerase (Stratagene, La Jolla, CA) from clone $553 \mathrm{H} 3$ of the RPCI.22 BAC library (Invitrogen, Eugene, OR) and subcloned into the pLD53.SCA-E-B shuttle vector (a gift from N. Heintz, Rockefeller University, New York, NY). Shuttle vector DNA was electroporated into electrocompetent bacteria and cells were selected in Luria Broth medium containing carbenicillin and chloramphenicol overnight. This culture was diluted 1:1000 and grown overnight, further diluted 1:5000 and grown for $8 \mathrm{~h}$, then plated on carbenicillin/chloramphenicol growth plates. Individual colonies were selected and cointegrates were screened for insertion of the transgene by PCR (Advantage Polymerase Mix; Clontech, Mountain View, CA). Sequences of primers (see Fig. 1a) were as follows: P1, 5'-GCAAACAGAAGAGACATCGCTAGC-3'; P2, 5'-CCTATGAAGCAGGGAGTTTTATTGC-3'; P3, 5'-GCAGGGAGTGACATTCTCTCTCC-3'; P4, 5'-GGAGAGAGAATGTCACTCCCTGC-3'; GFP1, 5'-CGAACTCCAGCAGGACCATG-3'; GFP2, 5'-CAAGTCGCACAGGCCGCTCC-3'. Cointegrates were further resolved by plating on TE-agar plates supplemented with chloramphenicol and 5\% sucrose. Modified BAC clones were screened by PCR and verified by Southern blotting using the upstream flanking region as a probe (supplemental Fig. 1, available at www.jneurosci.org as supple-

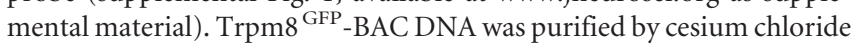
gradients and injected into the pronucleus of fertilized ova at the University of Southern California (USC) Transgenic Core Facility. Transgenic founder mice were identified by PCR and mated to C57BL/6 mice. All animals were handled and cared for in accordance with guidelines established by the USC Animal Care and Use Committee.

Immunostaining. Adult transgenic mice, aged 6-8 weeks, were anesthetized and perfused transcardially with $0.1 \mathrm{~m}$ PBS plus Heparin (7 U $\mathrm{ml}^{-1}$ ) followed by fixative [ $4 \%$ formaldehyde, $0.2 \%(\mathrm{v} / \mathrm{v})$ saturated picric acid, $0.1 \mathrm{M} \mathrm{PBS}, \mathrm{pH} 7.3$, at $4^{\circ} \mathrm{C}$ ]. Tissues were carefully dissected and post-fixed for $2 \mathrm{~h}$ at $4^{\circ} \mathrm{C}$ in the same fixative. For oral structures, fixed samples were decalcified in cold $10 \%$ ethylenediaminetetraacetic acid (EDTA, pH 7.4), changed daily for 5-10 d, and then were rinsed in PBS for $30 \mathrm{~min}$. All tissues were cryoprotected in $20 \%$ sucrose, $0.1 \mathrm{M}$ PBS at $4^{\circ} \mathrm{C}$ for $24 \mathrm{~h}$, quick frozen in OCT, sectioned with a cryostat at $20 \mu \mathrm{m}$, and mounted on Superfrost Plus slides. Slides were stored at $-80^{\circ} \mathrm{C}$. Frozen slides were dried at $24^{\circ} \mathrm{C}$ for $30 \mathrm{~min}$ and washed with deionized water for $30 \mathrm{~s}$.

Slide-mounted sections were washed three times with PBS, once with PBS plus $0.1 \%$ Triton X-100 (PBS-TX) for $30 \mathrm{~min}$, and three times with PBS before a blocking step ( $1 \mathrm{~h}$ in PBS-TX containing $10 \%$ goat serum).
Primary antibodies were diluted in a working solution (1\% BSA, $1 \mathrm{M}$ lysine, and $0.1 \% \mathrm{NaN}_{3}$ in PBS). These antibodies and dilutions were used: 1:2000 rabbit anti-GFP (A-11122; Invitrogen), 1:500 chicken antiGFP (GFP-1020; Aves Labs, Tigard, OR), 1:500 guinea pig anticalcitonin gene-related peptide (CGRP; T-5027; Peninsula, San Carlos, CA), 1:1000 rabbit anti-human protein gene product (PGP) 9.5 (AB1761; Millipore, Temecula, CA), 1:1000 rabbit anti-NF200 (N-4142; Sigma, St. Louis, MO), 1:500 rabbit anti-peripherin (AB1530; Millipore), 1:2000 rabbit anti-PKC $\gamma$ (c-19; catalog \# s.c.-211; Santa Cruz Biotechnology, Santa Cruz, CA), 1:500 rabbit anti-transient receptor potential vanilloid 1 (TRPV1; RA14113; Neuromics, Edina, MN), and 1:500 rabbit anti-TRPM8 (a gift from M. Tominaga, Okazaki Institute for Integrative Bioscience, Okazaki, Japan). Sections were washed three times with PBS-TX and incubated for $3 \mathrm{~h}$ at room temperature with secondary antibodies conjugated to Alexa-488 or Alexa-568 (Invitrogen) diluted 1:1000 in blocking solution. To detect IB4 binding, we included 1:2000 Griffonia simplicifolia isolectin GS-IB4-Alexa 568 (I-21412; Invitrogen) during secondary antibody incubations. Sections were washed five times with PBS-TX and mounted in Vectorshield mounting medium with DAPI, or PermaFluor mounting medium (Thermo Fisher Scientific, Pittsburgh, PA). Digital images were acquired on a Zeiss (Oberkochen, Germany) AxoImager Z1 with Apotome attachment. Quantification of overlap between GFP expression and that of other neuronal markers was obtained per field and expressed as percentage overlap with the SE between fields.

Cell culture and calcium microfluorimetry. Trigeminal and dorsal root ganglia (DRGs) were dissected from newborn transgenic mice and dissociated with $0.25 \%$ collagenase P (Roche Applied Science, Indianapolis, $\mathrm{IN}$ ) in a solution of $50 \%$ DMEM (with $4.5 \mathrm{~g}$ D-glucose, L-glutamine, and sodium pyruvate; Mediatech, Washington, DC) and 50\% F-12 (Ham's F-12 nutrient mixture with L-glutamine; Invitrogen) for $30 \mathrm{~min}$ at $37^{\circ} \mathrm{C}$ (McKemy et al., 2002). The ganglia were then pelleted and resuspended in $0.05 \%$ trypsin at $37^{\circ} \mathrm{C}$ for $2 \mathrm{~min}$, and gently triturated with a firepolished Pasteur pipette in culture medium (DMEM/F-12 with 10\% FBS and penicillin-streptomycin). The cells were enriched by Percoll density gradient centrifugation and then resuspended in culture medium with nerve growth factor $7 \mathrm{~S}$ (100 $\mathrm{ng} \mathrm{ml}^{-1}$; Invitrogen) and plated onto coverslips coated with Matrigel $\left(20 \mu \mathrm{l} \mathrm{ml}^{-1}\right.$; BD Biosciences, San Jose, CA). Cultures were examined 16-20 h after plating using Fura-2 calcium microfluorimetry. Menthol sensitivity was assayed using a $200 \mu \mathrm{M}$ menthol solution and only cells that also responded to $50 \mathrm{~mm} \mathrm{KCl}$ were included in the cell counts. For immunostaining, acute cultures were fixed in $4 \%$ PFA for $30 \mathrm{~min}$ at $4^{\circ} \mathrm{C}$ and then processed as described for frozen tissue sections.

Mammalian cell electrophysiology. Whole-cell voltage-clamp recordings of menthol-evoked currents in GFP-expressing trigeminal neurons were performed as described previously (McKemy et al., 2002). Standard bath solution for whole-cell recordings contained (in $\mathrm{mm}$ ) $140 \mathrm{NaCl}, 5 \mathrm{KCl}, 1 \mathrm{MgCl}_{2}, 2 \mathrm{CaCl}_{2}, 10$ HEPES, and 10 glucose, $\mathrm{pH} 7.4$ (adjusted with $\mathrm{NaOH}$ ). The pipette solution for whole-cell recordings contain (in mM) $140 \mathrm{CsCl}$, 0.02 EGTA, 2 MgATP, 10 HEPES, pH 7.4 (adjusted with $\mathrm{CsOH}$ ). Recordings were performed using an Axopatch 200B amplifier (Molecular Devices, Palo Alto, CA) and Digidata 1320 data acquisition board (Molecular Devices) with pCLAMP software (Molecular Devices). Solutions were exchanged by gravity fed tubes connected to an eight-channel perfusion valve solution controller (Warner Instruments, Hamden, CT) and fed into a recording chamber (Warner Instruments). The temperature of the perfusate was controlled by a perfusion temperature controller (RDTC-1; E.S.F. Electronic, Goettingen, Germany) peltier system. This same device also measured the temperature of the bath solution via a small thermocouple located in the recording chamber. All drugs used were stored and handled following the manufacturers' instructions.

\section{Results}

\section{Generation of BAC transgenic mice expressing GFP via the Trpm8 promoter}

The critical role of TRPM8 in cold signaling is remarkable in that very few sensory neurons express this channel (McKemy et al., 

TRPM8
Gene
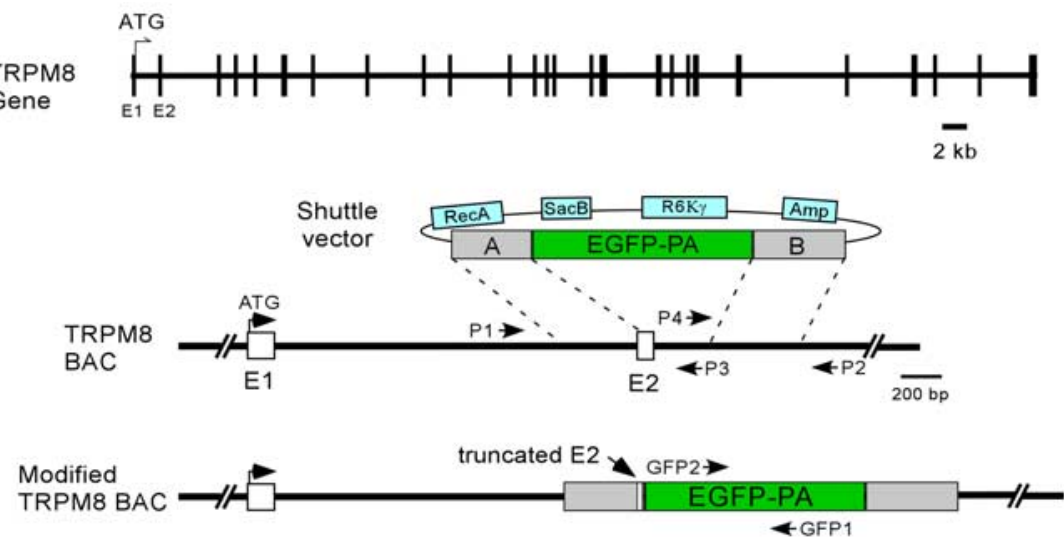

b
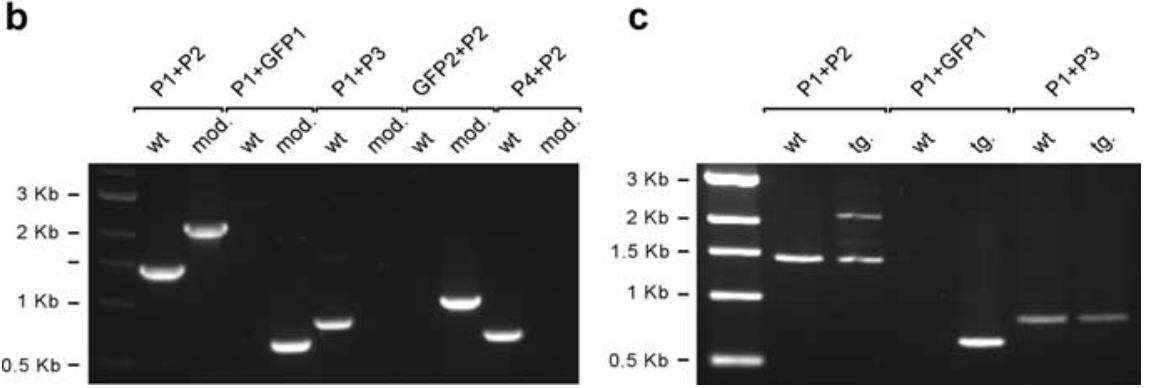

Figure 1. Generation of Trpm $8^{G F P}$ BAC transgenic mice. $a$, The Trpm 8 gene contains 26 exons, with the initiator ATG residing in exon 1 (E1). The Trpm8 $8{ }^{\text {GFP }}$-BAC modification strategy targeted the enhanced GFP coding sequence with a PGK-polyA fragment (EGFP-PA; green box) to the second coding exon (E2; white box). Gray boxes indicate sequences used for homologous recombination and blue boxes are shuttle vector sequences for the Escherichia coli Rec $A$ gene (RecA), the negative selection marker sac $B$

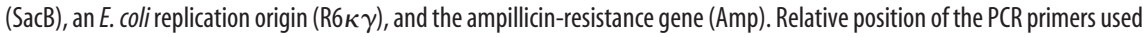
for screening of cointegrates, resolved modified clones, and genomic DNA are as indicated. $\boldsymbol{b}$, PCR screening of the modified Trpm8 BAC clone (mod) with an unmodified BAC clone [wild-type (wt)] as control. Position of primers for each reaction are those depicted in $\boldsymbol{a}$. Note that primers specific to GFP sequences (GFP1 and GFP2) do not produce PCR products in wt bacteria, whereas similarly, those that are in genomic regions deleted after transgene insertion ( $\mathrm{P3}$ and $\mathrm{P} 4$ ) are equally absent from mod bacteria. $\boldsymbol{c}$, Mouse tail genomic DNA was used as template for PCR with primer pairs depicted in $\boldsymbol{a}$. PCR products obtained using wt and transgenic mouse (tg) DNA indicate integration of the GFP transgene.

2002; Peier et al., 2002). Indeed, the paucity of neurons that express TRPM8 has made the study of this thermosensor and these cells problematic at best. TRPM8 RNA transcripts are found in $\sim 10 \%$ of either DRG or trigeminal ganglion (TG) soma (McKemy et al., 2002; Peier et al., 2002), and the current models for expression come largely from in situ hybridization analyses (Peier et al., 2002; Nealen et al., 2003; Kobayashi et al., 2005). Thus, to more readily identify TRPM8 neurons both in vivo and in vitro, we established a line of transgenic mice, using BAC clone transgenesis, in which cell-specific expression of enhanced GFP is driven by the $\operatorname{Trpm} 8$ transcriptional promoter. BAC clones are advantageous over standard transgenic approaches in that clones contain large sequences $(>150 \mathrm{~Kb})$ that typically include an entire transcription unit of a particular gene. Therefore, the associated regulatory units that are usually absent from conventional transgenic constructs are included, negating the positional effects that can lead to lack of, or incorrect, expression in traditional transgenic approaches (Gong et al., 2002). We modified a BAC clone containing sequences corresponding to the $\operatorname{Tr} p m 8$ genomic locus by targeting a GFP transgene to sequences equivalent to the second exon of the mouse Trpm 8 gene (Fig. 1a,b). Modified BAC DNA was purified on $\mathrm{CsCl}_{2}$ gradients and injected into the pronucleus of fertilized ova at the USC Transgenic Core Facility. Founder mice were identified by PCR $\left(\operatorname{Trpm} 8^{G F P}\right)$ (Fig. 1c), and all mice showed no obvious behavioral or phenotypic abnormalities.

To characterize the extent of transgene expression, we first examined GFP expression in adult mouse (6-8 weeks) sensory ganglia and observed robust fluorescence in $12.9 \%$ of neurons $(n=513)$, with average cell diameters of $18.9 \pm 0.5 \mu \mathrm{m}$ and $17.0 \pm 0.4 \mu \mathrm{m}$ for DRG $(n=127)$ and TG $(n=120)$ neurons, respectively (Fig. $2 a, b)$. These values are analogous to those obtained previously for TRPM8 expression in mice (Peier et al., 2002; Bautista et al., 2007). Interestingly, $\mathrm{GFP}^{+}$soma size ranged from 10 to $30 \mu \mathrm{m}$, with the majority of cell sizes indicative of small-diameter $\mathrm{C}$-fibers and the remainder corresponding to small- to medium-diameter A $\delta$-fibers (Fig. 2b) (Lawson and Waddell, 1991). Next, we determined that GFP expression correlates with TRPM8 using immunochemistry and functional cellular recordings. First, we confirmed that transgene expression was neuronal-specific by examining GFP expression in relation to the panneuronal marker PGP 9.5, finding that GFP fluorescence was restricted to cultured cells labeled with the neuronal marker (Fig. 3a). Second, we correlated GFP fluorescence with TRPM8 immunoreactivity using affinity purified rabbit anti-rat TRPM8 antiserum (Bautista et al., 2007), finding that $90.8 \pm 1.8 \%$ of $\mathrm{GFP}^{+}$neurons $(n=297)$ were immunoreactive for TRPM8 (Fig. 3b). Similar results were obtained with acutely cultured TG neurons where we observed that $91.0 \pm 3.4 \%$ of $\mathrm{GFP}^{+}$neurons $(n=$ 168) were immunoreactive for TRPM8 (data not shown). Last, we examined the functional characteristics of $\mathrm{GFP}^{+}$neurons using $\mathrm{Ca}^{2+}$. microfluorimetry and whole cell voltage-clamp recordings. When challenged with $200 \mu \mathrm{M}$ menthol, we found that $81.5 \pm$ $4.8 \%$ cultured GFP ${ }^{+}$neurons (Fig. $\left.3 c, d\right)(n=265)$ responded with robust increases in intracellular $\mathrm{Ca}^{2+}$. Similarly, menthol evoked robust, adapting, outwardly rectifying ionic currents in $\mathrm{GFP}^{+}$neurons (Fig. $\left.3 e, f\right)(n=7)$. These responses are consistent with those reported previously for TRPM8 currents recorded in menthol-sensitive rat sensory neurons and heterologous cells expressing TRPM8 (McKemy et al., 2002). Thus, these data demonstrate that GFP (Trpm $\left.8{ }^{\text {GFP }}\right)$ labels sensory afferents expressing TRPM8 in vivo and in vitro.

\section{TRPM8 is expressed in both nociceptive and non-nociceptive} sensory neurons

With the specific expression of GFP in TRPM8 neurons, we set out to determine the neurochemical phenotype of these cells compared with a range of classical somatosensory neuronal markers. Somatosensory neurons are routinely segregated into largely nonoverlapping subclasses based on a number of parameters, such as the extent of axonal myelination, or the presence of neuropeptides (Silverman and Kruger, 1988; Goldstein et al., 1991; Hunt and Mantyh, 2001). However, these markers do not select for the modality of stimuli that specific neurons detect, 
whereas TRP channel expression can molecularly demarcate neurons functionally (Jordt et al., 2003). Nonetheless, it remains to be determined if neurons expressing a particular thermosensitive TRP channel can be further divided into distinct functional groups. To begin to address this issue for cold-sensitive neurons, we determined the neurochemical phenotype of $\mathrm{GFP}^{+}$ neurons (Fig. 4, supplemental Fig. 2, available at www.jneurosci.org as supplemental material). Consistent with previous reports, at no time did we observe colabeling of Trpm $8^{\text {GFP }}$ with IB4 binding (Fig. $4 a$, supplemental Fig. $2 a$, available at www. jneurosci.org as supplemental material) (Peier et al., 2002; Abe et al., 2005; Kobayashi et al., 2005). However, a number of Trpm $8{ }^{\text {GFP }}$ neurons (Fig. $4 f$ ) were immunoreactive for the intermediate filaments NF200 (TG, $25.5 \pm 2.6 \%, n=329$; DRG, $13.9 \pm 3.7 \%, n=129)$ and peripherin (TG, $28.0 \pm 3.8 \%, n=239$; DRG, $24.8 \pm 2.8 \%$, $n=272$ ). The overlap with NF200 (Fig. $4 b$, supplemental Fig. $2 b$, available at www. jneurosci.org as supplemental material) and peripherin (Fig. 4c, supplemental Fig. $2 c$, available at www.jneurosci.org as supplemental material) immunoreactivity demonstrates that TRPM8 neurons have both $\mathrm{A} \delta$ - and C-fibers, respectively (Lawson and Waddell, 1991), consistent with the large deficits in cold-evoked discharges observed in both fibers-types of TRPM8-null mice (Bautista et al., 2007). Interestingly, the proportion of $\mathrm{GFP}^{+}$neurons that were immunoreactive for NF200 (putative A $\delta$-fibers) was smaller in DRG than TG (Fig. 4f), suggesting a difference in the extent of innervation of distinct cold-fiber types in these respective tissues. More strikingly, a large proportion of TRPM8 neurons do not label with either intermediate filament ( $\sim 40 \%$ in TG and $60 \%$ in DRG), an observation consistent with transcript analyses (Peier et al., 2002) and suggests that these cells represent a population of small diameter afferent neurons that can only be categorized by TRPM8 expression.

In situ hybridization studies have reported a lack of overlap between TRPM8 and TRPV1 expression, leading to the suggestion that the former is not expressed in nociceptors and therefore not involved in signaling noxious cold (Peier et al., 2002; Story et al., 2003). However, behavioral studies with TRPM8-null mice show that TRPM8 does serve a role in noxious cold sensing, but that it is likely not the sole determinant (Bautista et al., 2007; Colburn et al., 2007; Dhaka et al., 2007). Moreover, functional data from cultured sensory neurons show that approximately one-half of menthol-sensitive neurons are also capsaicinsensitive, suggesting coexpression of both TRPM8 and TRPV1 in this subset of cold- and menthol-sensitive neurons (McKemy et al., 2002; Viana et al., 2002; Hjerling-Leffler et al., 2007). Last, in primary culture, a subset of menthol-sensitive DRG neurons has been shown to have nociceptive properties (Xing et al., 2006). Thus, we examined coexpression of GFP and TRPV1 immunoreactivity in TG and DRG and, consistent with functional data, found that $38.8 \pm 2.2 \%(n=719)$ and $23.7 \pm 4.6 \%(n=221)$ of
$\mathrm{GFP}^{+}$TG and DRG soma also express TRPV1, respectively (Fig. $4 d, f$, supplemental Fig. $2 d$, available at www.jneurosci.org as supplemental material). Additionally, we observed a significant overlap between GFP fluorescence and immunoreactivity for the neuropeptide CGRP (Fig. 4e, supplemental Fig. $2 e$, available at www.jneurosci.org as supplemental material) in both sets of ganglia, although as with TRPV1, more trigeminal $\mathrm{GFP}^{+}$neurons were represented as peptidergic than those of the dorsal root ganglia (Fig. $4 f$ ) (TG, $32.1 \pm 3.1 \%, n=511$; DRG, $19.9 \pm 2.4 \%$, $n=288$ ). Nonetheless, as predicted from behavioral and functional data, a fraction of TRPM8 neurons can be considered putative nociceptors neurochemically, providing a cellular rationale for the role of this channel in detecting both innocuous and noxious thermal stimuli. Whether these presumptive nociceptors (TRPM8/TRPV1-expressing neurons) account for all cold nociceptors remains to be determined. Moreover, these results suggest that trigeminal ganglia are more enriched in cold nociceptors, as indicated by TRPM8 expression, a result consistent with the robust sensitivity of regions innervated by trigeminal neurons.

Peripheral TRPM8 ${ }^{+}$fibers are asymmetrically distributed to peripheral structures that mediate perceptually distinct cold sensations

Our data show that Trpm 8 GFP soma are heterogeneous neurochemically, with expression in both $\mathrm{C}$ - and $\mathrm{A} \delta$-fibers and presumptive nociceptors, findings that suggests involvement of 

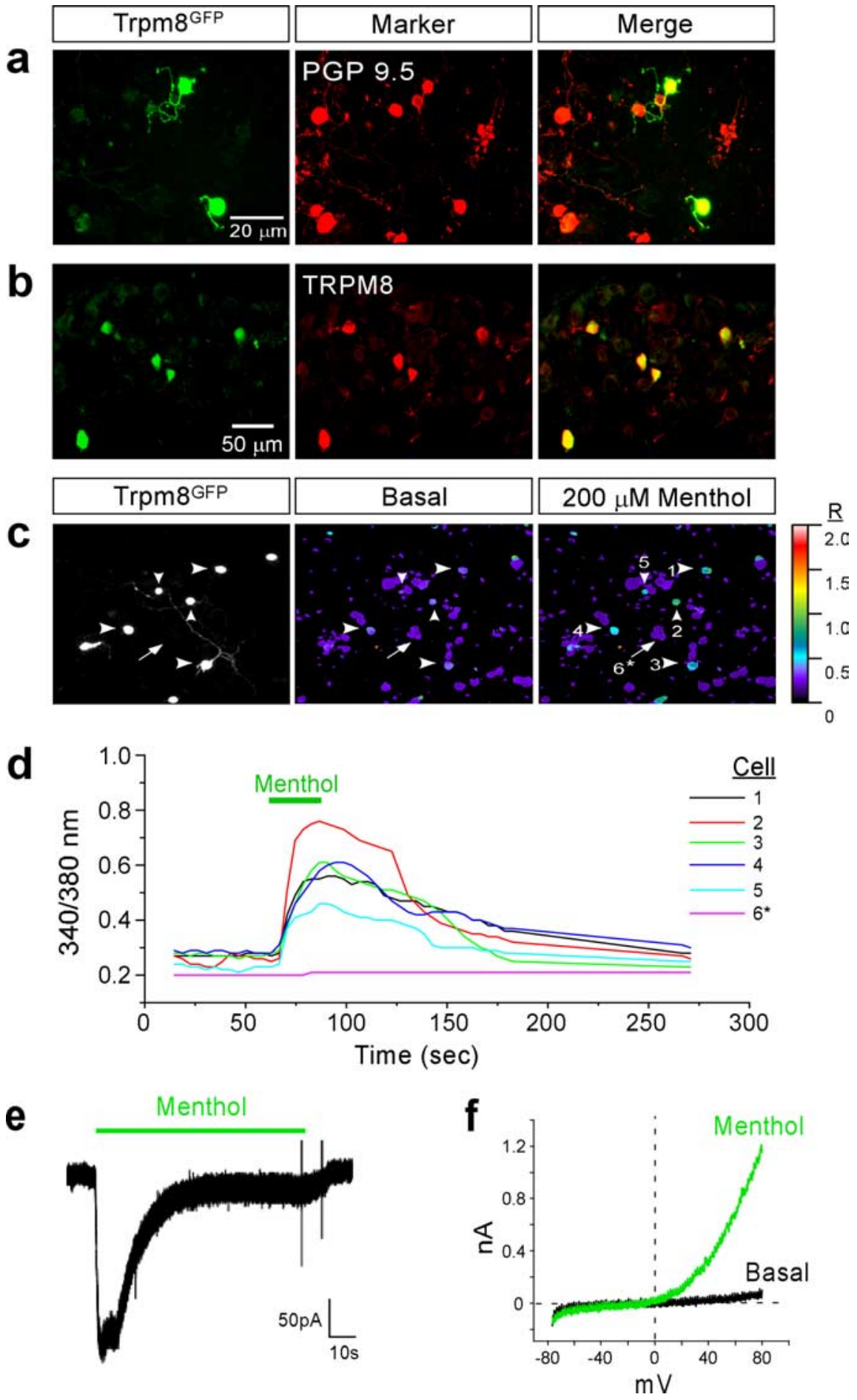

Figure 3. GFP labels TRPM8 neurons in vivo and in vitro. $\boldsymbol{a}, 0$ ne-day-old cultured TG neurons show robust GFP fluorescence (green) that colocalizes with immunoreactivity for the pan-neuronal marker PGP 9.5 (red). $\boldsymbol{b}$, 0verlap in GFP fluorescence and TRPM8-immunoreactivity in sensory ganglia. Paraformaldehyde-fixed cryosections of trigeminal ganglia from adult Trpm $8^{G F P}$ mice were immunostained with anti-TRPM8 antibodies and GFP fluorescence (green) was correlated with TRPM8- IR (red). c, Menthol sensitivity of Trpm $8{ }^{\text {GFP }}$ neurons. GFP ${ }^{+}$trigeminal neurons (left) from Trpm $8^{\text {GFP }}$ mice respond with robust increases in intracellular $\mathrm{Ca}^{2+}$ when challenged with $200 \mu \mathrm{m}$ menthol. Pseudo-colored images (middle and right panels) of ratio values for the $\mathrm{Ca}^{2+}$ indicator fura-2 were used to identify menthol-sensitive neurons (right). $\boldsymbol{d}$, Fura-2 ratio values for the images shown in c indicate the time course of $\mathrm{Ca}^{2+}$ responses in GFP ${ }^{+}$neurons (arrowheads). Numbering corresponds to the cells shown in c. * Note that cell 6 (arrow) was negative for GFP and did not respond to menthol. e, A representative whole-cell voltage-clamp recording from a GFP ${ }^{+} \mathrm{TG}$ neuron in culture. Menthol $(200 \mu \mathrm{M})$ was applied during the time indicated by the green bars and the membrane potential was held at $-60 \mathrm{mV}$.f, Current-voltage relationship of basal (black) and menthol-evoked (200 $\mu \mathrm{m}$, green) currents in a GFP ${ }^{+}$TG neuron in culture show the expected voltage dependence and outward rectification of TRPM8-mediated currents.
TRPM8 in both nociceptive and nonnociceptive sensory signaling. These results are consistent with the phenotype of TRPM8-null mice, which are deficient in many aspects of cold sensing, including innocuous cold discrimination and nocifensive responses to noxious cold (Chung and Caterina, 2007). Moreover, psychophysical and functional data have shown cool fibers and noxious cold fibers to have distinct receptive zones in peripheral tissues (DarianSmith et al., 1973; Jyvasjarvi and Kniffki, 1987; Davis, 1998). Thus, we examined various peripheral structures including teeth, palate, tongue, and skin to determine whether TRPM8 fibers innervate these tissues in a manner that suggests that they may mediate both innocuous and noxious cold signaling, hypothesizing expression in functionally distinct subtypes of neurons or neural circuits. The most well studied for localization of receptive zones of distinct cold fiber types are the tooth dentin and pulp (Byers and Narhi, 2002). In humans, cooling the tooth evokes a first pain that is described as sharp, transient and shooting, which is then followed by a second delayed dull aching pain (Hensel, 1982; Jyvasjarvi and Kniffki, 1987). Similarly, in animal models, cold stimulation of teeth evokes activity first in $\mathrm{A} \delta$-fibers, which respond with high-frequency discharges that have short latencies and adapt quickly (Jyvasjarvi and Kniffki, 1987). C-fibers respond concurrently to the same cold stimulus with longer latencies and low frequency, nonadapting discharges (Fig. $5 a$ ). Thus, the first and second pains evoked by cold stimulation of the tooth are attributed to coldsensitive $\mathrm{A} \delta$ - and C-fibers, respectively (Jyvasjarvi and Kniffki, 1987). More critically, cold-sensitive $\mathrm{A} \delta$ - and C-fibers in both cats and rats have distinct receptive fields, with superficial endings of $\mathrm{A} \delta$-fibers located to the dentin and C-fibers deeper in the pulp (Fig. 5a) (Jyvasjarvi and Kniffki, 1987; Byers and Narhi, 2002).

Because we observed GFP in both Cand $A \delta$-fibers neurochemically in TG neurons, we hypothesized that TRPM8 is expressed in both intradentinal and pulpal fibers in the tooth and thus mediates both first and second pain sensations. Consistent with this hypothesis, we observed $\mathrm{GFP}^{+}$fibers in Trpm $8^{G F P}$ mouse molars to cross the odontoblast layer that demarcates the pulp-dentin border and extend into the dentinal tubules (Fig. 5b, arrowheads), indicating that these are $A \delta$-fibers (Jyvasjarvi and Kniffki, 1987; Byers and Narhi, 2002). We also compared tooth regions innervated by TRPM8 fibers to both CGRP- and peripherin-positive fibers. In the rat, nerve 
endings of CGRP-fibers are asymmetrically distributed in both the pulp and dentin, with some axons crossing the odontoblast layer demarcating the pulp-dentin border (Byers and Narhi, 2002; Veerayutthwilai et al., 2006). In Trpm $8^{G F P}$ mouse molars, we observed $\mathrm{GFP}^{+}$axons to cross the odontoblast layer in a manner similar to $\mathrm{CGRP}^{+}$ fibers (Fig. $5 c$, arrowheads). Additionally, GFP and CGRP axon terminals were found in the deep pulp layers (Fig. $5 c$, arrows, boxed region), and a number of these coexpressed both GFP and CGRP. In contrast we found that, as in the rat, the odontoblast layer in $\operatorname{Trpm} 8^{G F P}$ mouse molars were mostly devoid of peripherin-immunoreactive axons (Fig. $5 d$, arrowheads). These axons extended toward the odontoblast layer but then turned away, thereby being restricted to the pulp (Veerayutthwilai et al., 2006), whereas GFP axons extended through this layer and entered the dentin (Fig. $5 d$, arrows). Together, these data show that TRPM8 fibers are localized to the dentin and strongly support the hypothesis that cold activation of $A \delta$-fibers in the tooth is mediated by TRPM8.

In addition to dentinal localization of TRPM8 fibers, we also observed $\mathrm{GFP}^{+}$axons in the pulp (Fig. 5c). Thus, we examined GFP expression in pulp-restricted fibers to determine whether they also bear the hallmarks of cold-sensitive C-fibers that may mediate the second pain sensation associated with cold. Recall that in colabeling experiments in sensory ganglia, onequarter of $\mathrm{GFP}^{+}$TG soma were immunoreactive for the $\mathrm{C}$-fiber marker peripherin (Fig. $4 c, f$ ), and that peripherin ${ }^{+} \mathrm{C}$-fibers are restricted to tooth pulp (Fig. $5 d$ ) (Veerayutthwilai et al., 2006). Thus, we examined $\mathrm{GFP}^{+}$axons for peripherinimmunoreactivity in the tooth pulp to determine whether these are indeed C-fibers. In double labeling experiments where $\operatorname{Trpm} 8^{G F P}$ mouse molars were cut in cross section, we found a fraction of presumptive TRPM8 axons to colabel with peripherin (Fig. $6 a$, arrowheads), thereby recapitulating the neurochemical phenotype in ganglia and demonstrating this population of $\mathrm{GFP}^{+}$axons to be C-fibers. Moreover, we found that a number of $\mathrm{GFP}^{+}$axons in the pulp also label with CGRP and NF200 (Fig. 6b,c), further corroborating our coexpression data in sensory ganglia. Thus, TRPM8 neurons are made up of both A $\delta$ - and C-fibers in the tooth, and these results, taken with both functional recordings in animals and psychophysical data in humans, suggests that TRPM8 can serve dual roles in cold signaling based on expression in functionally and anatomically distinct fiber types.
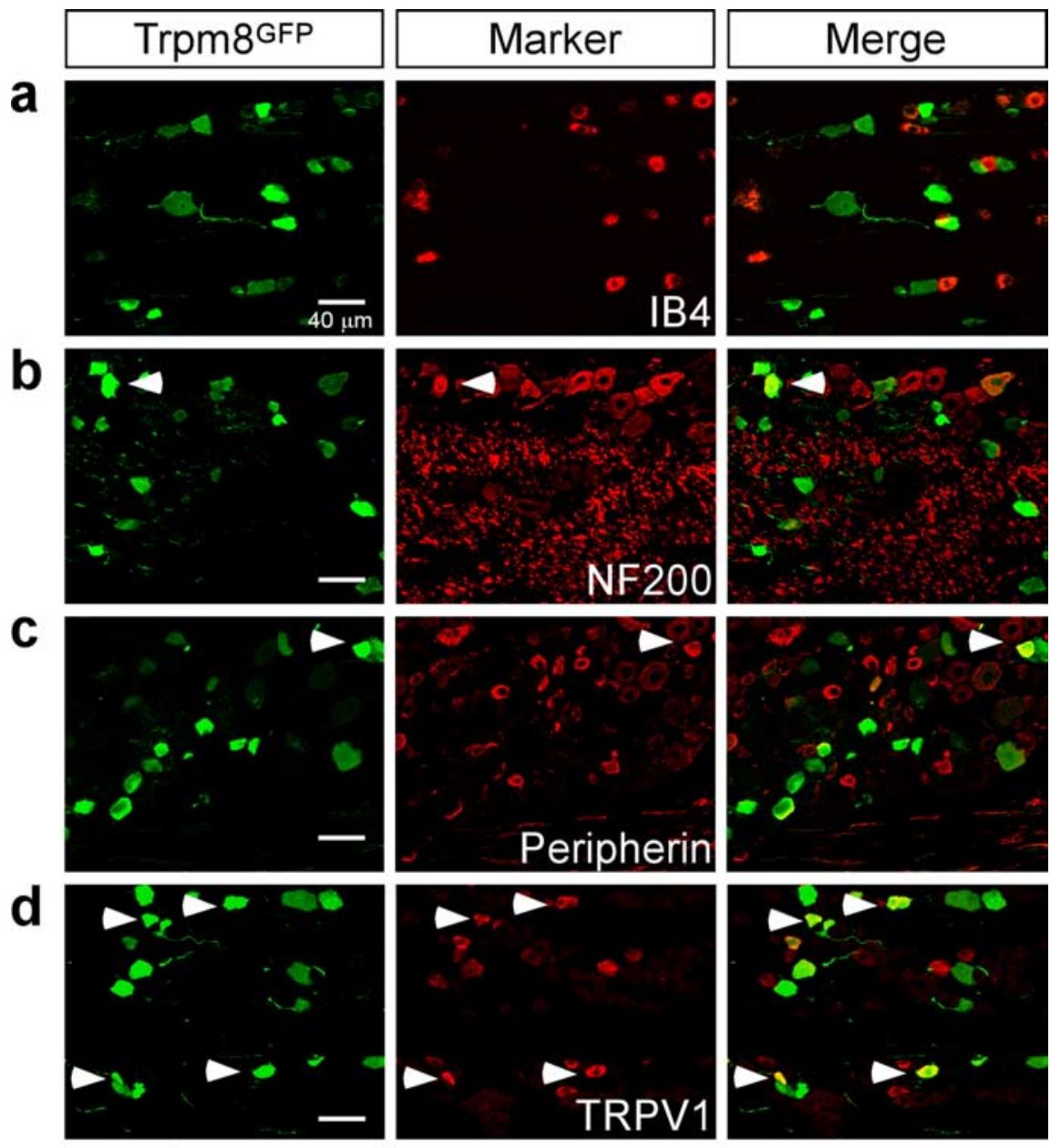

e
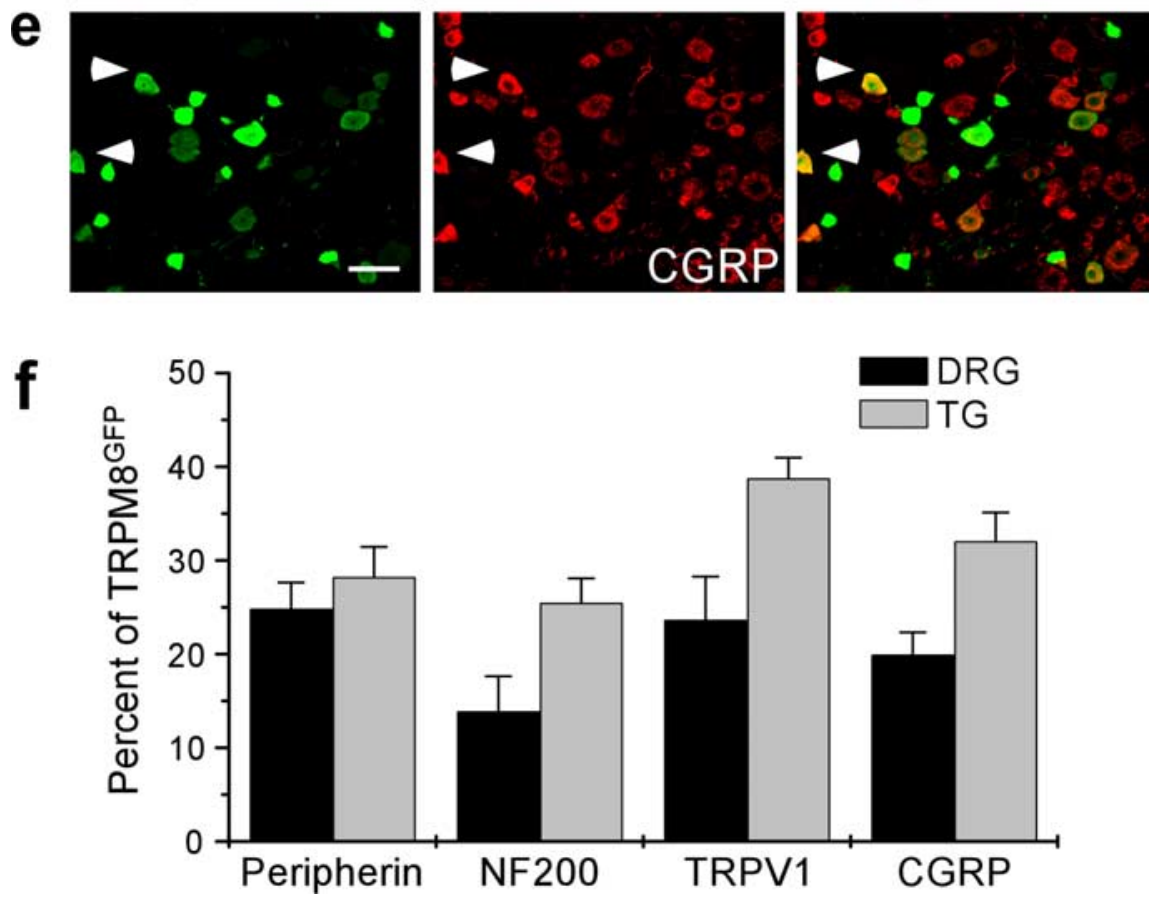

Figure 4. Trpm8 GFP expression colocalizes with a diverse array of afferent markers in TG neurons. $\boldsymbol{a}-\boldsymbol{e}$, In trigeminal ganglia harvested from adult Trpm $8^{G F P}$ mice, a fraction of GFP labeled neurons (green) colabel (arrowheads) with a number of afferent markers (red), as indicated. Scale bars: $40 \mu \mathrm{m}$ in all images and similar images shown for dorsal root ganglia neurons in supplemental Figure 2 (available at www.jneurosci.org as supplemental material). $\boldsymbol{a}$, Of note, no GFP fluorescence was observed in IB4-positive neurons. $f$, Quantification of the percentage of GFP ${ }^{+}$DRG and TG neurons that are also immunoreactive for the neural markers indicated. Numbers are means of colabeled cells with the SEs per microscopic field. 
a

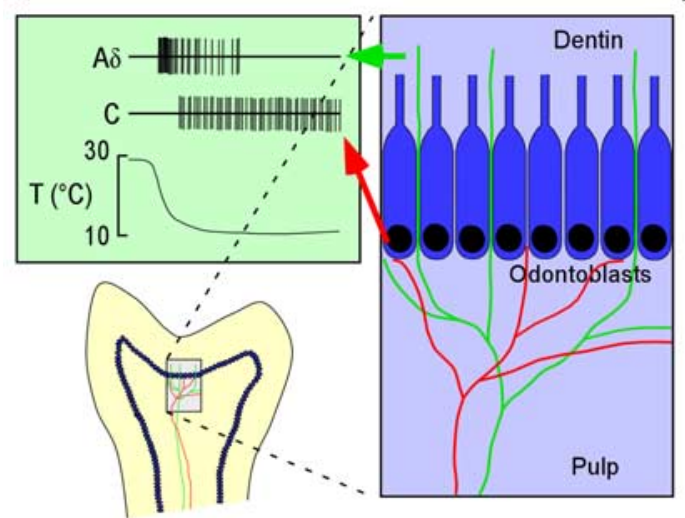

b
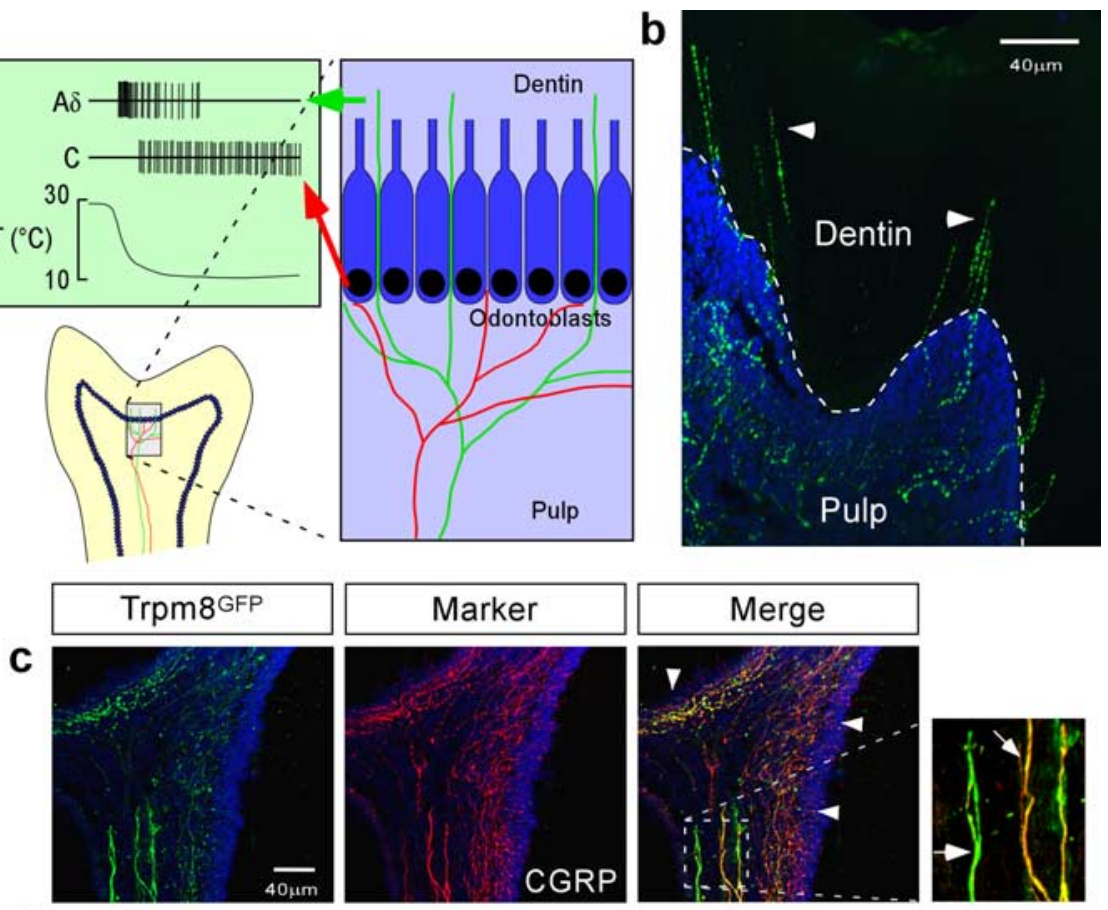

d
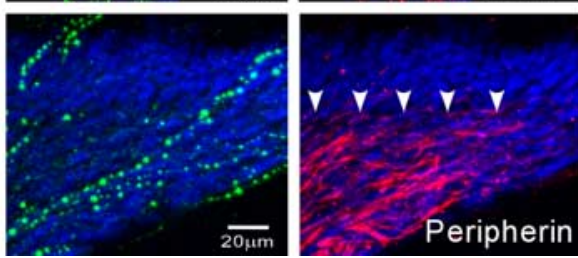

Figure 5. Peripheral terminals of Trpm 8 GFP axons are found in functionally distinct regions in the tooth. $a$, Schematic diagram of mouse molars indicating the termination zones of cold-sensitive C- (red) and A $\delta$-fibers (green) localized in the pulp and dentin, respectively. Cell rich odontoblast layer that separates the pulp and dentin is shown in blue (blue box). During a cold stimulus, $\mathrm{C}$-and $\mathrm{A} \delta$-fibers fire with distinct rates of discharge, latencies, and adaptation, as depicted in green box [schematic and data modeled after that of Byers and Narhi (2002) and Jyvasjarvi et al. (1987), respectively]. $\boldsymbol{b}$, In a longitudinal section of a decalcified molar, Trpm8 ${ }^{\text {GFP }}$ fibers (green) cross the odontoblast layer located at the pulp-dentin border (dashed line) and extend into the dentin (arrowheads). Cell nuclei were stained with DAPI (blue). $\boldsymbol{c}, \boldsymbol{d}$, Immunostaining of mouse molars reveals Trpm8 ${ }^{\text {GFP }}$ axons are morphologically and neurochemically distinct. c, Colabeling of Trpm8 ${ }^{\text {GFP }}$ (green) and CGRP (red) axons in mouse molars show that both fiber types have asymmetrically distributed terminals that reside in the pulp (arrows in boxed region) and extend into the dentin (arrowheads). $\boldsymbol{d}$, Peripherin fibers (red) extend to, but do not enter the odontoblast layer (boundary marked by arrowheads), whereas Trpm8 ${ }^{\text {GFP }}$ fibers (green) extend through and into the dentin (arrows).

\section{TRPM8 nerve endings are localized in both deep and superficial regions of skin and palate}

We next set out to determine whether this diversity in receptive zones innervated by TRPM8 fibers is restricted to the tooth, or also occurs in other peripheral tissues. The skin is the largest sensory organ in the body and provides critical information about the external environment. Nociceptive and thermosensitive fibers terminate as free nerve endings in the epidermis, but little is known of the peripheral organization of fibers involved in detecting discrete sensory modalities. Some insights into peripheral innervation of specific fiber types have come from labeling of cutaneous and central terminations of peptidergic and nonpeptidergic fibers. Previous studies using genetically labeled nonpeptidergic fiber types report that these axons terminate in a distinct epidermal zone superficial to that of peptidergic fibers (Zylka et al., 2005; Liu et al., 2007), suggesting distinct topography for different fiber types. Although these elegant studies described the peripheral and central terminations of these fibers, they must still be considered heterogeneous functionally as they are not ascribed to mediating a specific sensory modality. For cold-sensitive nerves, psychophysical and functional data suggest that innocuous cool fibers are located superficial to noxious cold fibers in the skin (Davis, 1998; Harrison and Davis, 1999). These data, along with our findings that TRPM8 neurons are both peptidergic and nonpeptidergic, led us to ask whether the peripheral terminals of $\mathrm{GFP}^{+}$axons are restricted to a single epidermal domain, or terminate throughout the epidermis in a manner indicative of disparate functional fiber types.

Using Trpm $8^{G F P}$ mice, we examined the organization of peripheral terminals ascribed to a specific sensory modality (i.e., cold sensing) in dermal and epidermal regions in the skin and oral epithelium. Because different skin types display a range of cold sensitivity (Davis, 1998; Harrison and Davis, 1999), we first looked to see if Trpm8 ${ }^{\text {GFP }}$ fibers innervate either hairy or glabrous skin. In hairy skin, we found $\mathrm{GFP}^{+}$axonal endings in the most superficial layers and positioned generally along, but not associated with hair follicles (Fig. $7 a$ ). We next examined localization of Trpm $8{ }^{\text {GFP }}$ axon terminals in glabrous skin where the epidermis is separated into 4 distinct layers (Fig. 7c) demarcated by keratinocyte organization (Rice et al., 1997; Zylka et al., 2005). Unlike the segregated topography of peptidergic versus nonpeptidergic axonal endings in the epidermis (Zylka et al., 2005), we found Trpm $8{ }^{\text {GFP }}$ axon terminals near the epidermal/dermal boundary (Fig. $7 b$ ) and in the stratum granulosum (SG), the most superficial live cell layer of the epidermis (Fig. 7c). The same was true in the palate and tongue where $\mathrm{GFP}^{+}$axon terminals were observed in both the outermost regions of the epithelium and in deeper zones distinct from superficial GFP axons (supplemental Fig. 3, available at www.jneurosci.org as supplemental material). Next we compared the localization of $\mathrm{GFP}^{+}$axons with that of other fiber types, such as GFP-negative CGRP- and NF200-fibers. As in the tooth, in some sections there was colocalization of GFP with these markers (data not shown). However, in many sections what initially appeared to be colocalization was in fact two fibers intertwined (Fig. $7 d, e$ ). These observations are consistent with the small percentage of peptidergic and nonpeptidergic fibers that are intimately associated in the periphery and are likely innervating the same cutaneous zone (Zylka et al., 2005). We did not directly compare $\mathrm{GFP}^{+}$axon terminals with those of nonpeptidergic fibers as these are obscured by IB4 binding in keratinocytes (Rice, 1993). However, based on previous analyses (Zylka et al., 2005), our results demonstrate that, unlike the distinct topographical separation of peptidergic and nonpeptidergic afferents in the epidermis, fibers defined by a modality specific marker, namely TRPM8, innervate a diverse range of cutaneous domains. Although this diversity correlates with the range of psychophysical cold responses (Davis, 1998; Harrison and Davis, 1999), it 
remains to be seen if fibers localized to separate domains do indeed have distinctive functional properties.

\section{Central projections of TRPM8 fibers in the dorsal spinal cord}

Our data reveal that cold fibers, as defined by TRPM8 expression, are diffusely dispersed throughout various peripheral structures. We next asked whether the central projections of TRPM8 fibers are similarly diverse. The central projections of thermosensory and nociceptive afferents terminate in the superficial spinal cord dorsal horn, where they converge at multiple synapses that encode these peripheral signals along ascending pathways (Christensen and Perl, 1970; Craig, 2003). In the rat, those that express the heat-gated channel TRPV1 are known to predominately terminate in lamina I and II, although some fibers are observed deeper in lamina $\mathrm{V}$ and $\mathrm{X}$ (Tominaga et al., 1998). It is likely that cold fibers have similar central projections, suggested by peripheral cold induction of $c$-fos expression, an indicator of neural activity, in superficial lamina (Todd et al., 2005).

Consistent with this observation we found robust GFP fluorescence in the superficial dorsal horn in sections of $\operatorname{Trpm} 8^{G F P}$ mouse spinal cords (Fig. $8 a-c$ ). In colabeling experiments, we asked which lamina receives input from Trpm 8 GFP fibers. Peptidergic fibers, labeled by CGRP immunoreactivity, project to lamina I and the outer regions of lamina II (IIo) (McNeill et al., 1988; Zylka et al., 2005). In contrast, nonpeptidergic neurons labeled by IB4-binding project primarily to the inner region of lamina II (IIi), whereas lamina IIi and III can be visualized by labeling of interneurons expressing the $\gamma$-isoform of protein kinase C (PKC $\gamma$ ) (Silverman and Kruger, 1988; Hunt and Mantyh, 2001; Zylka et al., 2005). In spinal cords of Trpm $8^{G F P}$ mice, there was almost complete overlap of GFP- and CGRPlabeled fibers (Fig. $8 d$ ), but little to no overlap with IB4 binding (Fig. 8e). Indeed, there was separation between central projections of Trpm $8{ }^{\text {GFP }}$ fibers and those that bind IB4 (Fig. $8 f$ ). This distinct segregation is in contrast to central projections of TRPV1-fibers in the rat, which overlap with IB4-binding terminals in the medial part of inner lamina II (Tominaga et al., 1998). Last, there was no overlap of $\operatorname{Trpm} 8{ }^{\mathrm{GFP}}$ fibers with spinal interneurons that express PKC $\gamma$ (Fig. $8 g$ ). We did observe a small number of $\mathrm{GFP}^{+}$fibers in deeper lamina (Fig. $8 b$, arrowheads), consistent with similar observations for rat TRPV1 fibers (Tominaga et al., 1998). Nonetheless, these data demonstrate that TRPM8 fibers terminate primarily in lamina I and IIo, as would be predicted for thermosensory and nociceptive afferents, but are restricted to more defined termination zones than TRPV1 fibers.

\section{Discussion}

Thermosensitive TRP ion channels molecularly distinguish modality-specific neuronal populations, yet it remains to be seen if these neurons are functionally homogeneous, or have multiple subpopulations that mediate different aspects of thermal signaling. Although TRPM8 is restricted to a small subset of sensory neurons, it is critical in most aspects of cold sensation (Bautista et al., 2007; Colburn et al., 2007; Dhaka et al., 2007). Even more notable, the channel is key in the analgesia provided by moderate cooling and modest doses of cooling compounds (Proudfoot et al., 2006; Dhaka et al., 2007). Thus, both in vitro and in vivo data suggests a single molecule, expressed on a small number of sensory axons, mediates many aspects of sensory signaling depending on the quality of the stimulus and tissue state. This poses a number of interesting questions, such as how can a single molecule accomplish these various tasks in vivo? Also, why is channel activation analgesic under some conditions and painful in others? To address these questions, a more thorough assessment of TRPM8 neurons functionally, molecularly, and anatomically is required (McKemy, 2005).

Here, we have begun this process and show that TRPM8 neurons are a heterogeneous mix of both putative nociceptors and non-nociceptors. Even more striking is that a large percentage of these neurons do not fit into a traditional neurochemical pheno- 

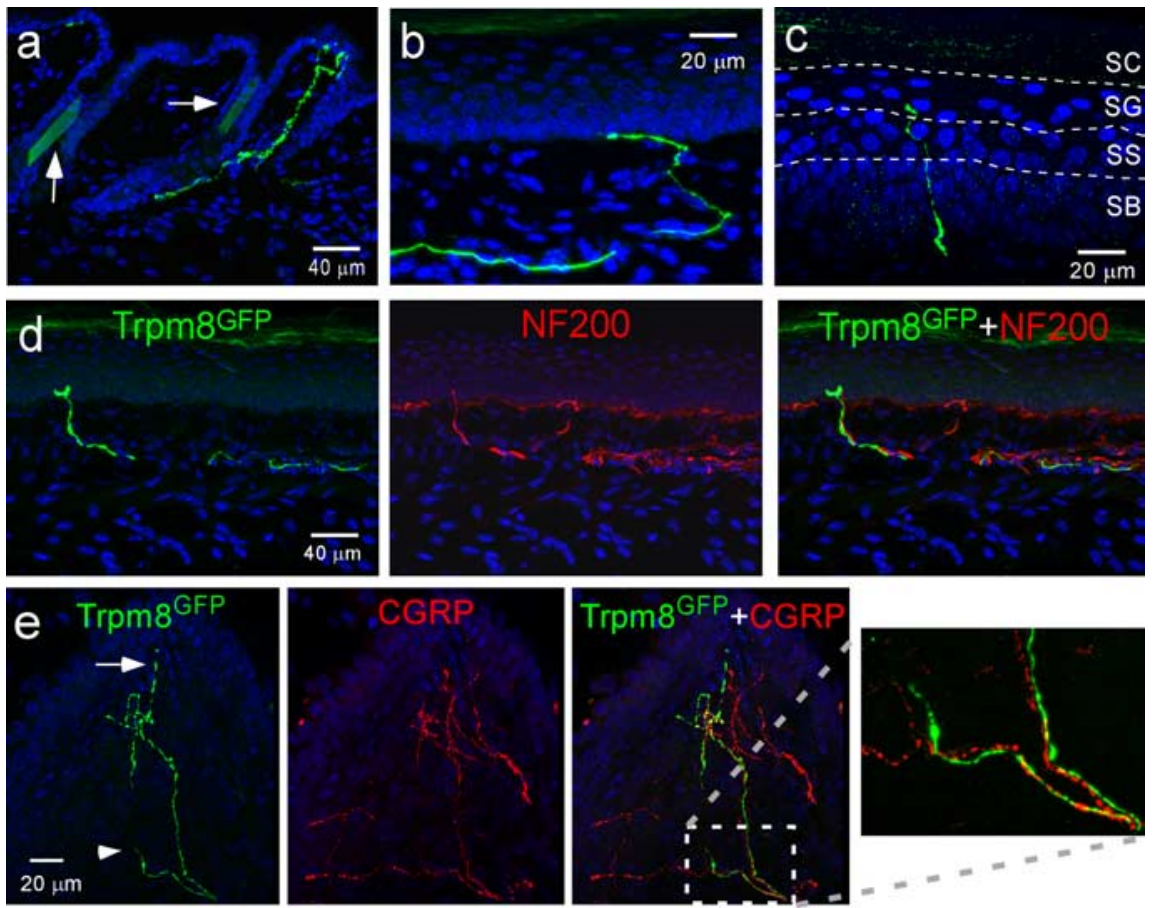

Figure 7. Trpm $8{ }^{\text {GFP }}$ axon terminals innervate diverse sites in the skin and oral cavity. $\boldsymbol{a}-\boldsymbol{d}$, Sections through both hairy $(\boldsymbol{a})$ and glabrous skin $(\boldsymbol{b}-\boldsymbol{d})$ of mouse hind limb reveal Trpm $8{ }^{\text {GFP }}$ nerve endings in both superficial epidermal regions $(\boldsymbol{a}, \boldsymbol{c})$ and at or near the epidermal/dermal boundary $(\boldsymbol{b}, \boldsymbol{d})$. Nuclei (blue) were counterstained with DAPI. $\boldsymbol{a}$, In hairy skin Trpm8 ${ }^{\text {GFP }}$ fibers are located superficially and near hair follicles (arrows). $\boldsymbol{b}, \boldsymbol{c}, \operatorname{Trpm} 8^{\mathrm{GFP}}$ fibers terminate in the stratum granulosum (SG; $\boldsymbol{c}$ ), as well as in the stratum basalis (SB; $\boldsymbol{b})$. Designation of other epidermal domains: stratum spinosum (SS) and stratum corneum (SC) and are marked as in the study by Zylka et al. (2005). $\boldsymbol{d}$, Trpm8 ${ }^{\text {GFP }}$ axons are observed to intertwine with other fiber types (red, NF200-positive A-fiber), terminating in the same peripheral domain. $\boldsymbol{e}$, In the rugal palate, colocalization of GFP ${ }^{+}$fibers with CGRP-immunoreactive fibers. Enlarged image reveals that Trpm8 ${ }^{\text {GFP }}$ and CGRP axons intertwine, as well as GFP ${ }^{+}$endings are located in both superficial (arrow) and deep epithelial layers (arrowhead).

type. For example, if one considers the classical markers of peptidergic and nonpeptidergic neurons (Hunt and Mantyh, 2001), one-third of TRPM8 TG neurons are immunoreactive for CGRP (even fewer in DRG), whereas none bind IB4. However, based on these criteria, over two-thirds of TRPM8 TG neurons fall outside of this classification (i.e., those that are CGRP and IB4 negative).

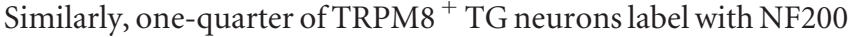
whereas an equal but distinct population label for peripherin. Thus, about one-half of these cold fibers are negative for either marker, accounting for $\sim 5 \%$ of all TG neurons (one-half of $12.9 \%)$. This number is even greater considering that fewer $\mathrm{TRPM}^{+}{ }^{+}$DRG neurons were NF200 positive. Additionally, as sensory afferents expressing TRPV1 and CGRP are considered to be largely nociceptors, coexpression of these markers with Trpm $8{ }^{\text {GFP }}$ demonstrates that a portion of TRPM8 neurons are putative nociceptors and that activation of neurons coexpressing TRPV1 may account for the sensation of burning pain that occurs at cold extremes (Yarnitsky and Ochoa, 1990; Davis, 1998; Mauderli et al., 2003). Interestingly, Trpm $8{ }^{\mathrm{GFP}}$ was observed in neurons that label with either marker exclusively, or with both CGRP and TRPV1, further demonstrating diversity of channel expression, in this case in nociceptors (supplemental Fig. 4, available at www.jneurosci.org as supplemental material). Thus, our results demonstrate that the small number of neurons expressing TRPM8 is a molecularly diverse mix, a multiplicity that likely belies distinct functionalities in subsets of these cold-sensing neurons. The next goal will be to define the role of these different neuronal subsets and how they contribute to our perception of cold temperatures.
Our analysis of the localization of TRPM8 axon terminals in peripheral tissues supports the hypothesis that TRPM8 serves as a temperature sensor in nerve fibers that communicate multiple yet distinct cold sensations. No where is this more evident than in the densely innervated mouse molars. Indeed, teeth are advantageous in this regard because of the anatomical segregation of functionally distinct fiber types (Jyvasjarvi and Kniffki, 1987; Byers and Narhi, 2002; Veerayutthwilai et al., 2006). We found Trpm $8{ }^{\mathrm{GFP}}$ to label superficial intradental $\mathrm{A} \delta$-fibers, as well as pulpal C-fibers. Because cold-evoked discharges are diminished in both $\mathrm{A} \delta$ - and C-fibers of TRPM8-null mice (Bautista et al., 2007), we propose that the first and second pain sensations attributed to each are mediated by this lone molecular thermoreceptor. However, this hypothesis needs to be validated by electrophysiological recordings from these anatomically distinct fibers in intact preparations (Koltzenburg et al., 1997; Bautista et al., 2007).

Whereas localization of TRPM8 endings in the pulp is consistent with models of sensory signaling in the tooth (Matthews, 1977; Park et al., 2006), Trpm8 ${ }^{\text {GFP }}$ expression in fibers entering the dentin is surprising. Strong experimental evidence suggests that sensory afferents innervating the dentin are activated via hydrodynamic receptors detecting fluid movement through dentinal tubules, a process termed the dentinal hydrodynamic theory (Matthews, 1977; Byers and Narhi, 2002; Park et al., 2006; Chidchuangchai et al., 2007). Thus, intradental afferents are thought to be activated by a mechanism detecting changes in movement, not temperature (Chidchuangchai et al., 2007). However, previous evidence suggests that, in the case of cold stimulation, alternative mechanisms may also be in play (Chidchuangchai et al., 2007). Combining in vivo pain ratings in humans and in vitro measurements of tubule fluid flow, Chidchuangchai et al. (2007) demonstrated that exposure of dentinal tubules increased cold pain, but conversely decreased fluid movement (Chidchuangchai et al., 2007). This conflicts with the hydrodynamic theory and predicts that the greatest cold-evoked afferent discharge occurs when fluid flow rates are at their lowest, prompting the authors to suggest that cold-pain involves other transduction mechanisms such as cold receptors (Chidchuangchai et al., 2007). Our observation of Trpm $8{ }^{\text {GFP }}$ fibers in dentine supports this hypothesis. One caveat is that we are observing expression of a transgene and not the receptor itself. Although unlikely, it is possible that GFP is free to fully transport to nerve endings in the tubules, but TRPM8 channels are restricted to regions out of the dentin, such as in the predentin or pulp.

The skin relays an array of thermal information critical for survival (McKemy, 2007). In humans, cold is perceived to be of greater intensity in glabrous skin than in hairy skin, with cold and pain thresholds occurring at warmer skin temperatures in the former (Harrison and Davis, 1999). This disparity is attributed to differences in tissue thickness and composition, but is likely also attributable to the extent of innervation by thermoreceptors 
(Davis, 1998; Morin and Bushnell, 1998; Harrison and Davis, 1999). In addition, acuity of cold intensity is disparate, with the sensations of heat pain and warmth similar in that they quickly dissipate after stimulus removal (Morin and Bushnell, 1998). The same is true for innocuous cool, but not for painful cold, the perception of which persists for up to $10 \mathrm{~s}$ after warming of the skin (Morin and Bushnell, 1998). These results suggest that afferent terminals involved in detecting innocuous cool are in the superficial epidermis, whereas cold nociceptors are located deeper. Indeed, psychophysical studies of cold and cold pain such as these lead Davis to the suggestion that cold stimuli "affect a mosaic of primary afferent input” (Davis, 1998). Our results are consistent with this hypothesis as we observe Trpm $8{ }^{\text {GFP }}$ axonal endings superficially in the stratum granulosum, as well as deeper near the epidermal/dermal boundary. Although not definitive, these data suggest that TRPM8, as predicted by the phenotype of TRPM8-null mice (Bautista et al., 2007; Colburn et al., 2007; Dhaka et al., 2007), mediates the perception of innocuous cool and noxious cold, a hypothesis that needs to be validated electrophysiologically.

Last, the robust expression of GFP has also allowed us to characterize the laminar domains of their central projections in the spinal cord dorsal horn. Central TRPM8 projections enter the dorsal horn and terminate primarily in the most superficial lamina, consistent with their identity as thermosensory and nociceptive fibers (Julius and Basbaum, 2001). To understand the coding of somatosensory signals, it will be key to identify the second-order projection neurons and interneurons in the spinal cord that are synaptically coupled with modality-specified sensory afferents. Several subtypes of projection neurons receiving and integrating input from afferents responding to multiple modalities have been identified (Han et al., 1998). With our ability to genetically label select and modality-specific afferents based on TRP channel expression, the identification and mapping of somatosensory neural circuits should be feasible.

In conclusion, the preponderance of evidence coming from human, animal, and cellular studies suggests that the neural substrates for cold signaling are diverse. However, previous analyses of TRPM8-null mice suggest that this lone ion channel is the prime molecular detector of cold, and initiates the majority of these responses (Bautista et al., 2007; Colburn et al., 2007; Dhaka et al., 2007). Here, we provide evidence that TRPM8 is expressed in several neuronal subtypes and that, although it endows these cells with cold sensitivity, other mechanisms likely help determine the resulting perceptual outcome of their activation. Whether different TRPM8 expressing afferents are endowed with distinct functional properties, or are in segregated neural circuits, needs to be addressed by functional recordings in intact preparations and circuit tracings in vivo. Such analyses of these and other
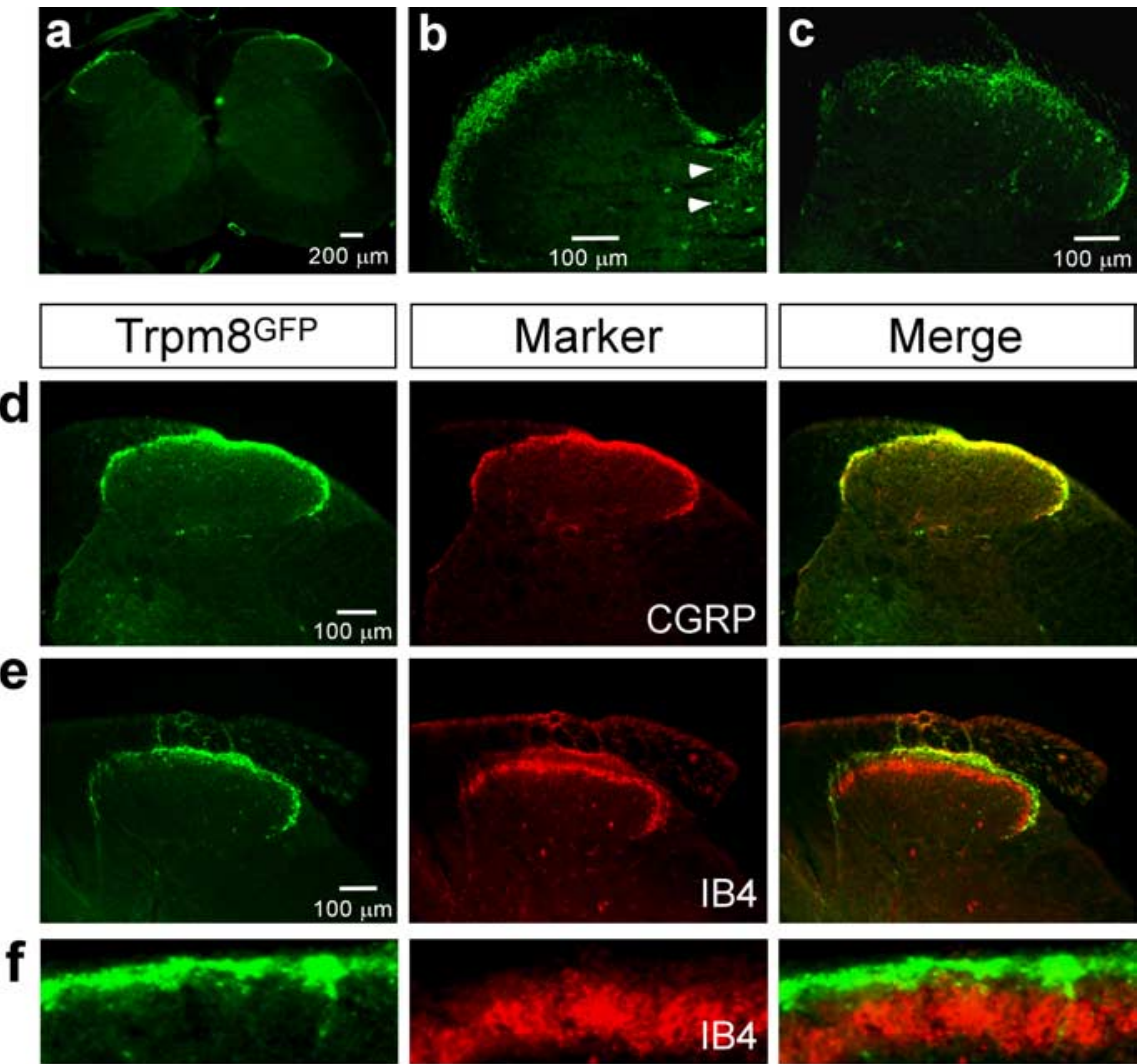

IB4
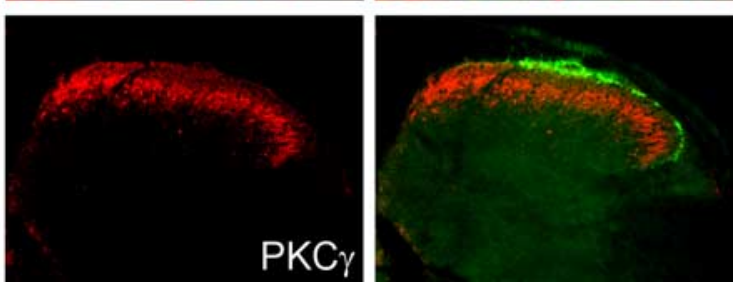

Figure 8. Central Trpm $8{ }^{\text {GFP }}$ axons terminate in superficial lamina of the spinal cord dorsal horn. $\boldsymbol{a}$, GFP fluorescence reveals central axons of Trpm8 ${ }^{\text {GFP }}$ neurons in the dorsal horn of Trpm $8^{G F P}$ mouse spinal cords. $\boldsymbol{b}, \boldsymbol{c}$, Immunostaining with anti-GFP the presence of Trpm8 ${ }^{\text {GFP }}$ projections deeper in the dorsal horn. $\boldsymbol{d}$, Trpm8 ${ }^{\text {GFP }}$ axons and CGRP-immunoreactive axons terminate in the same lamina of the spinal cord. $\boldsymbol{e}, \boldsymbol{g}, \operatorname{Trpm} 8{ }^{\mathrm{GFP}}$ axon terminals do not overlap with those that bind IB4 (e) or with interneurons that are immunoreactive for $\operatorname{PKC} \gamma(\boldsymbol{g})$. $\boldsymbol{f}$, Closer examination reveals that there is little overlap of $\operatorname{Trpm} 8{ }^{\text {GFP }}$ fibers and those that bind IB4, indicating distinct central terminals for each fiber type.

afferent subtypes will shed light on the neural correlates of somatosensory signaling, establishing the basis for genetic manipulation of neural function, mapping of somatosensory neural networks, and elucidation of the intricacies of sensory coding in the somatosensory system.

\section{References}

Abe J, Hosokawa H, Okazawa M, Kandachi M, Sawada Y, Yamanaka K, Matsumura K, Kobayashi S (2005) TRPM8 protein localization in trigeminal ganglion and taste papillae. Brain Res Mol Brain Res 136:91-98.

Bautista DM, Siemens J, Glazer JM, Tsuruda PR, Basbaum AI, Stucky CL, Jordt SE, Julius D (2007) The menthol receptor TRPM8 is the principal detector of environmental cold. Nature 448:204-208.

Byers MR, Narhi, MV (2002) Nerve supply of the pulpodentin complex and responses to injury. In: Dental pulp (Hargreaves KM, Goodis HE, eds), pp 151-179. Carol Stream, IL: Quintessence.

Chidchuangchai W, Vongsavan N, Matthews B (2007) Sensory transduction mechanisms responsible for pain caused by cold stimulation of dentine in man. Arch Oral Biol 52:154-160.

Christensen BN, Perl ER (1970) Spinal neurons specifically excited by nox- 
ious or thermal stimuli: marginal zone of the dorsal horn. J Neurophysiol 33:293-307.

Chung MK, Caterina MJ (2007) TRP channel knockout mice lose their cool. Neuron 54:345-347.

Colburn RW, Lubin ML, Stone Jr DJ, Wang Y, Lawrence D, D'Andrea MR, Brandt MR, Liu Y, Flores CM, Qin N (2007) Attenuated cold sensitivity in TRPM8 null mice. Neuron 54:379-386.

Craig AD (2003) Pain mechanisms: labeled lines versus convergence in central processing. Annu Rev Neurosci 26:1-30.

Daniels RL, McKemy DD (2007) Mice left out in the cold: commentary on the phenotype of TRPM8-nulls. Mol Pain 3:23.

Darian-Smith I, Johnson KO, Dykes R (1973) “Cold" fiber population innervating palmar and digital skin of the monkey: responses to cooling pulses. J Neurophysiol 36:325-346.

Davis KD (1998) Cold-induced pain and prickle in the glabrous and hairy skin. Pain 75:47-57.

Dhaka A, Murray AN, Mathur J, Earley TJ, Petrus MJ, Patapoutian A (2007) TRPM8 is required for cold sensation in mice. Neuron 54:371-378.

Goldstein ME, House SB, Gainer H (1991) NF-L and peripherin immunoreactivities define distinct classes of rat sensory ganglion cells. J Neurosci Res 30:92-104.

Gong S, Yang XW, Li C, Heintz N (2002) Highly efficient modification of bacterial artificial chromosomes (BACs) using novel shuttle vectors containing the R6Kgamma origin of replication. Genome Res 12:1992-1998.

Han ZS, Zhang ET, Craig AD (1998) Nociceptive and thermoreceptive lamina I neurons are anatomically distinct. Nat Neurosci 1:218-225.

Harrison JL, Davis KD (1999) Cold-evoked pain varies with skin type and cooling rate: a psychophysical study in humans. Pain 83:123-135.

Hensel H (1982) Thermal sensations and thermoceptors in man. Springfield, IL: Charles C. Thomas.

Hjerling-Leffler J, Alqatari M, Ernfors P, Koltzenburg M (2007) Emergence of functional sensory subtypes as defined by transient receptor potential channel expression. J Neurosci 27:2435-2443.

Hunt SP, Mantyh PW (2001) The molecular dynamics of pain control. Nat Rev Neurosci 2:83-91.

Jordt SE, McKemy DD, Julius D (2003) Lessons from peppers and peppermint: the molecular logic of thermosensation. Curr Opin Neurobiol 13:487-492.

Julius D, Basbaum AI (2001) Molecular mechanisms of nociception. Nature 413:203-210

Jyvasjarvi E, Kniffki KD (1987) Cold stimulation of teeth: a comparison between the responses of cat intradental A delta and C fibres and human sensation. J Physiol (Lond) 391:193-207.

Kobayashi K, Fukuoka T, Obata K, Yamanaka H, Dai Y, Tokunaga A, Noguchi K (2005) Distinct expression of TRPM8, TRPA1, and TRPV1 mRNAs in rat primary afferent neurons with adelta/c-fibers and colocalization with trk receptors. J Comp Neurol 493:596-606.

Koltzenburg M, Stucky CL, Lewin GR (1997) Receptive properties of mouse sensory neurons innervating hairy skin. J Neurophysiol 78:1841-1850.

Lawson SN, Waddell PJ (1991) Soma neurofilament immunoreactivity is related to cell size and fibre conduction velocity in rat primary sensory neurons. J Physiol (Lond) 435:41-63.

Liu Q, Vrontou S, Rice FL, Zylka MJ, Dong X, Anderson DJ (2007) Molecular genetic visualization of a rare subset of unmyelinated sensory neurons that may detect gentle touch 10:946-948.

Matthews B (1977) Responses of intradental nerves to electrical and thermal stimulation of teeth in dogs. J Physiol (Lond) 264:641-664.

Mauderli AP, Vierck Jr CJ, Cannon RL, Rodrigues A, Shen C (2003) Relationships between skin temperature and temporal summation of heat and cold pain. J Neurophysiol 90:100-109.

McKemy DD (2005) How cold is it? TRPM8 and TRPA1 in the molecular logic of cold sensation. Mol Pain 1:16.
McKemy DD (2007) Temperature sensing across species. Pflugers Arch 454:777-791.

McKemy DD, Neuhausser WM, Julius D (2002) Identification of a cold receptor reveals a general role for TRP channels in thermosensation. Nature 416:52-58.

McNeill DL, Coggeshall RE, Carlton SM (1988) A light and electron microscopic study of calcitonin gene-related peptide in the spinal cord of the rat. Exp Neurol 99:699-708.

Morin C, Bushnell MC (1998) Temporal and qualitative properties of cold pain and heat pain: a psychophysical study. Pain 74:67-73.

Nealen ML, Gold MS, Thut PD, Caterina MJ (2003) TRPM8 mRNA is expressed in a subset of cold-responsive trigeminal neurons from rat. J Neurophysiol 90:515-520.

Park CK, Kim MS, Fang Z, Li HY, Jung SJ, Choi SY, Lee SJ, Park K, Kim JS, Oh SB (2006) Functional expression of thermo-transient receptor potential channels in dental primary afferent neurons: Implication for tooth pain. J Biol Chem 281:17304-17311.

Peier AM, Moqrich A, Hergarden AC, Reeve AJ, Andersson DA, Story GM, Earley TJ, Dragoni I, McIntyre P, Bevan S, Patapoutian A (2002) A TRP channel that senses cold stimuli and menthol. Cell 108:705-715.

Proudfoot CJ, Garry EM, Cottrell DF, Rosie R, Anderson H, Robertson DC, Fleetwood-Walker SM, Mitchell R (2006) Analgesia mediated by the TRPM8 cold receptor in chronic neuropathic pain. Curr Biol 16:1591-1605.

Reed RR (2004) After the holy grail: establishing a molecular basis for mammalian olfaction. Cell 116:329-336.

Rice FL (1993) Structure, vascularization, and innervation of the mystacial pad of the rat as revealed by the lectin Griffonia simplicifolia. J Comp Neurol 337:386-399.

Rice FL, Fundin BT, Arvidsson J, Aldskogius H, Johansson O (1997) Comprehensive immunofluorescence and lectin binding analysis of vibrissal follicle sinus complex innervation in the mystacial pad of the rat. J Comp Neurol 385:149-184.

Silverman JD, Kruger L (1988) Lectin and neuropeptide labeling of separate populations of dorsal root ganglion neurons and associated "nociceptor" thin axons in rat testis and cornea whole-mount preparations. Somatosens Res 5:259-267.

Story GM, Peier AM, Reeve AJ, Eid SR, Mosbacher J, Hricik TR, Earley TJ, Hergarden AC, Andersson DA, Hwang SW, McIntyre P, Jegla T, Bevan S, Patapoutian A (2003) ANKTM1, a TRP-like channel expressed in nociceptive neurons, is activated by cold temperatures. Cell 112:819-829.

Todd AJ, Spike RC, Young S, Puskar Z (2005) Fos induction in lamina I projection neurons in response to noxious thermal stimuli. Neuroscience 131:209-217.

Tominaga M, Caterina MJ, Malmberg AB, Rosen TA, Gilbert H, Skinner K, Raumann BE, Basbaum AI, Julius D (1998) The cloned capsaicin receptor integrates multiple pain-producing stimuli. Neuron 21:531-543.

Veerayutthwilai O, Luis NA, Crumpton RM, MacDonald GH, Byers MR (2006) Peripherin- and CGRP-immunoreactive nerve fibers in rat molars have different locations and developmental timing. Arch Oral Biol 51:748-760.

Viana F, de la Pena E, Belmonte C (2002) Specificity of cold thermotransduction is determined by differential ionic channel expression. Nat Neurosci 5:254-260.

Xing H, Ling J, Chen M, Gu JG (2006) Chemical and cold sensitivity of two distinct populations of TRPM8-expressing somatosensory neurons. J Neurophysiol 95:1221-1230.

Yarnitsky D, Ochoa JL (1990) Release of cold-induced burning pain by block of cold-specific afferent input. Brain 113:893-902.

Zylka MJ, Rice FL, Anderson DJ (2005) Topographically distinct epidermal nociceptive circuits revealed by axonal tracers targeted to mrgprd. Neuron 45:17-25. 